\title{
Investigation of change in different properties of sandstone and dolomite samples during matrix acidizing using chelating agents
}

\author{
Mian Umer Shafiq ${ }^{1,2}$ (D) Hisham Khaled Ben Mahmud' ${ }^{1}$ Muhammad Khurram Zahoor ${ }^{3} \cdot$ Arshad S. A. Shahid $^{3,4}$. \\ Reza Rezaee ${ }^{5}$ Muhammad Arif ${ }^{3,5}$
}

Received: 17 January 2019 / Accepted: 6 May 2019 / Published online: 15 May 2019

(c) The Author(s) 2019

\begin{abstract}
Properties of rock, such as effective porosity, permeability and pore size distribution (PSD), are generally referred to as petrophysical properties. These properties are among the most significant for reservoir evaluation. Acid stimulation treatments are usually used in sandstones to mitigate the impact of formation damage, with the aim of restoring or enhancing the natural matrix permeability and consequently boosting the well productivity. Hydrochloric acid $(\mathrm{HCl})$ is commonly used in the preflush stage to remove calcium and other metal ions, preventing the development of calcium fluoride $\left(\mathrm{CaF}_{2}\right)$ and other silicate precipitates that could block the pore throats, while an acid mixture ( $\mathrm{HF}-\mathrm{HCl}$ combination) is usually preferred as the main stimulation fluid for the removal of quartz and remaining metal ions. However, sometimes the application of these acids can lead to other problems, including fast reactions, corrosion of pipes, environmental hazards, precipitation reactions and formation damage due to the incompatibility of $\mathrm{HCl}$ with clay minerals, so chelating agents have been proposed as an alternative for matrix stimulation fluids. In this study, three different chelating agents, ethylenediaminetetraacetic acid (EDTA), $N$-(2-hydroxyethyl) ethylenediamine- $N, N^{\prime}, N^{\prime}$-triacetic acid (HEDTA) and $N$-acetyl-L-glutamic acid (GLDA), have been used to stimulate Berea sandstone, Colton tight sandstone and Guelph dolomite samples. Core flood experiments were conducted on $1.5 \times 3\left(\mathrm{in}^{2}\right)$ core plugs, at a temperature below $180^{\circ} \mathrm{F}$. A slow injection rate of $(1-0.5 \mathrm{cc} / \mathrm{min})$ was chosen for the treatment fluid, promoting the dissolution of ions by increasing the contact time between the fluid and the rock. Furthermore, nuclear magnetic resonance, wettability and micro-computed tomography (CT scan) analyses were employed to evaluate the effect of the acid treatment on formation properties such as porosity, PSD, pore topology, wettability and pore structure. After exposing the samples to HEDTA, large wormholes were detected in their pore network, demonstrating that HEDTA has the highest potential to create new pore spaces when compared to GLDA and EDTA when reacted with both types of samples.
\end{abstract}

Keywords Petrophysical $\cdot$ Pore topology $\cdot$ Wettability $\cdot$ HEDTA $\cdot$ Berea

Mian Umer Shafiq

umer.engr@hotmail.com

1 Department of Petroleum Engineering, Curtin University, Malaysia, Miri, Malaysia

2 Department of Petroleum and Gas Engineering, NFC IET, Multan, Pakistan

3 Department of Petroleum and Gas Engineering, University of Engineering and Technology, Lahore, Pakistan

4 Mineral Resources Engineering Group, Sejong University, Seoul, South Korea

5 Department of Petroleum Engineering, Curtin University, Perth, Australia

\section{Introduction}

According to the Organization of the Petroleum Exporting Countries OPEC (2016), it has been predicted that $14 \%$ more hydrocarbons will be required in 2040 as compared to 2014 . Table 1 shows the long-term reference case for the demand for oil, predicted by OPEC in the year 2016. (All values are in $\mathrm{MMbbl} / \mathrm{d}$.)

During acidizing, dolomite reservoirs are mostly soluble in acids, and acidizing in these reservoirs generates conductive pathways known as "wormholes" (Sidaoui and Sultan 2016). However, in sandstone reservoirs, only a small portion of the rock is soluble by acids and usually no wormholes 
Table 1 IEA long-term reference case (OPEC 2016)

\begin{tabular}{lrrrrrr}
\hline & 2015 & 2020 & 2025 & 2030 & 2035 & 2040 \\
\hline OECD & 46.2 & 45.9 & 44.3 & 42.1 & 39.7 & 37.3 \\
Developing countries & 41.5 & 46.8 & 52.2 & 57.4 & 62.0 & 66.1 \\
Eurasia & 5.3 & 5.6 & 5.8 & 6.0 & 6.1 & 6.0 \\
World & 93.0 & 98.3 & 102.3 & 105.5 & 107.8 & 109.4 \\
\hline
\end{tabular}

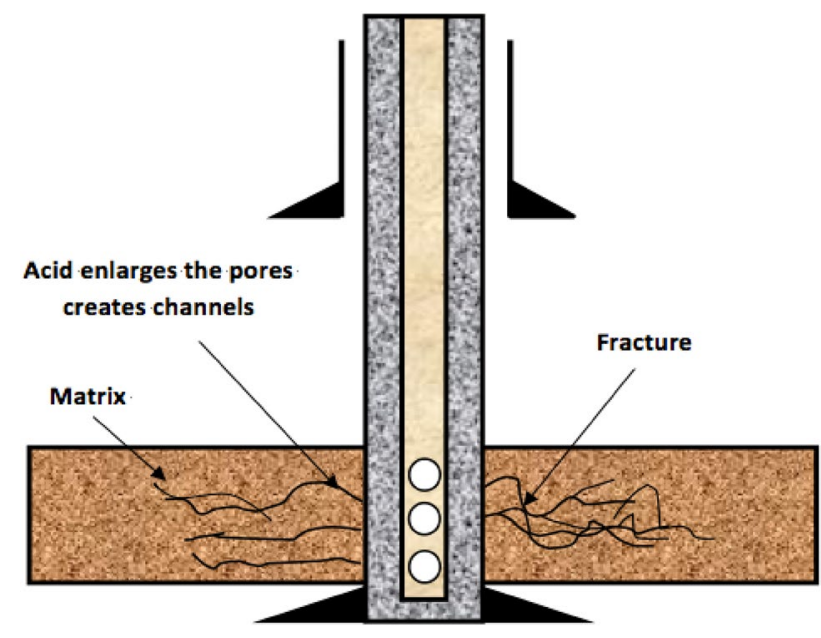

Fig. 1 Acid fracturing and matrix dissolution

are created. Figure 1 shows the matrix dissolution and acid fracturing.

Whenever the injection of acid is performed either at a pressure less or more than the fracture pressure of the formation, matrix dissolution occurs. Once the acid is injected with a pressure higher than the formation fracture pressure, it can create fractures (acid fracturing). Once the fractures are created, the acid then starts to react with the undamaged formation to remove the minerals (matrix acidizing) present inside the formation creating new pore spaces and channels. In order to enhance the hydrocarbon reservoir productivity, acidizing is considered one of the most effective and common techniques in the industry (Sidaoui and Sultan 2016). Acids play a key role in boosting production from hydrocarbon fields. Acidizing is a process in which injected fluid (mainly acid) in porous media reacts with matrix/minerals. This may lead to the variation in permeability and porosity due to the dissolution of rock minerals and re-precipitation of reaction products (Shafiq and Mahmud 2017).

Formation damage is detrimental to the hydrocarbon recovery as it causes extra pressure drop around the vicinity of the wellbore. During the well production, the largest pressure drop occurs in the area around the wellbore, which is a major target for matrix acidizing. This area usually extends (3-5 ft.) from the wellbore in dolomites and a few inches in a sandstone formation (Smith and Hendrickson 2013). This area is mainly damaged during drilling, production and completion operations, resulting in clay swelling, fines migration, drilling fluid invasion and deposition of scale during production (Al-Harthy 2008/2009). Therefore, the removal of formation damage is the main goal of sandstone and carbonate acidizing ( $\mathrm{Ji}$ et al. 2014). Thus, the original permeability of the formation can be restored or enhanced by creating new pore spaces. Therefore, acidizing is performed in order to reduce the damage and increase the productivity of fluids from the reservoir (Ghommem et al. 2015). This process improves the permeability by generating high-permeability flow paths and by removing the damage enhancing the well performance. Due to the presence of different minerals, sandstone acidizing process usually consists of multiple stages, which make it a very complicated and challenging task. During these stages, different acids react with different minerals, resulting in different reactions including precipitation reactions as well. These precipitation reactions can be counterproductive as they can cause a reduction in the reservoir permeability (Mahmoud et al. 2011).

A single strong mineral acid has the ability to dissolve rock particles, resulting in a reduction in formation damage and an increase in porosity and permeability and hence ultimately increasing the oil and gas production. Conversely, well tabular is exposed to high risk of corrosions due to the high reactivity of used acids (Johnson et al. 2016). In this research, the effect of chelates on the mineralogy, morphology, porosity, pore topology, pore size distribution and permeability of core samples has been investigated at a constant temperature value. The impact of chelating agents on conventional sandstone, dolomite and tight sandstone reservoirs can be understood by extensive study and research and applying new techniques. The successful application of chelating agents on conventional sandstones has raised interest in applying these chelates on dolomites and tight sandstone reservoirs. Experimental techniques and analyses such as nuclear magnetic resonance (NMR), permeability and porosity CT scan, wettability and change in pore volume have been used in this research to understand the effect of chelates on different formations. 
Table 2 Core samples and their properties

\begin{tabular}{|c|c|c|c|}
\hline & Berea (conventional sandstone) & Colton (tight sandstone) & Guelph dolomite \\
\hline \multicolumn{4}{|l|}{ Core sample } \\
\hline Company & Cleveland queries, Vermilion, Ohio, USA & $\begin{array}{l}\text { Kocurek Industries INC. Hard Rock } \\
\text { Division, Caldwell, Texas, USA }\end{array}$ & $\begin{array}{l}\text { Kocurek Industries INC. Hard } \\
\text { Rock Division, Caldwell, Texas, } \\
\text { USA }\end{array}$ \\
\hline \multirow[t]{3}{*}{ Properties } & Homogenous, clear sandstone & Homogenous, dirty sandstone & Heterogeneous, clean formation \\
\hline & Well sorted & Well sorted & Well sorted \\
\hline & Medium to fine grain size & Fine grain size & \\
\hline \multirow[t]{5}{*}{ Minerals } & 93-96\% Quartz & $59 \%$ Quartz & 97\% Ankerite \\
\hline & \multirow[t]{4}{*}{$3-5 \%$ Feldspar } & $10 \%$ Albite & $2.5 \%$ Dolomite \\
\hline & & $8 \%$ Calcite & \\
\hline & & $4 \%$ Ankerite & \\
\hline & & $3 \%$ Orthoclase & \\
\hline Porosity & $16-19 \%$ & $10-12 \%$ & $14-15 \%$ \\
\hline Permeability & $60-100 \mathrm{mD}$ & $1-2 \mathrm{mD}$ & $9-10 \mathrm{mD}$ \\
\hline
\end{tabular}

\section{Experimental studies}

\section{Chelating agents}

The saturated solutions of chelating agents have been prepared in distilled water. These chelates are basically complex acids, and dissociation in water is important for acidizing purpose. The dissociation is expressed in terms of equilibrium constant $\mathrm{pK}_{\mathrm{a}}$. These values can be used to determine the distribution of a chelating agent as a function of $\mathrm{pH}$. These chemicals (chelating agents) in purified solid form are purchased from the chemical supply. Tokyo Chemical Industry Co. LTD (TCI) provided GLDA and HEDTA, which are soluble in deionized water and showed acidic properties when $20 \mathrm{wt} \%$ a saturated solution is prepared, while EDTA is less soluble; therefore, its $5 \mathrm{wt} \%$ the solution is prepared in deionized water. The solubility of EDTA in deionized water is increased, and $20 \mathrm{wt} \%$ saturated solution can be prepared by increasing the temperature (which means at a high temperature the solubility increases and like other chelates $20 \%$ solution can be prepared).

\section{Core samples}

Sedimentary rocks are $46 \%$ shale, $32 \%$ sandstone and $22 \%$ carbonates in type (Leet and Judson 1971). From these sedimentary rocks, sandstone and carbonates are both porous and permeable; therefore, a huge volume of hydrocarbon is stored in sandstones and carbonate formations around the world. The core samples used in this experimental work mainly consist of different types of sandstones and dolomites in terms of permeability and porosity. The core samples could be divided into three different groups based on their origin, porosity and permeability ranges. Table 2 represents the properties of core samples used during the project.

\section{Core sample preparation}

Core cutting machine was used to cut the desired length of core samples. For core flooding experiments, the length of the core required was 3" with a diameter of 1.5", while for wettability analysis, small strip size samples were required as shown in Fig. 2. Figure 2 shows the smallest size of a core sample obtained from Berea sandstone, Colton sandstone and Guelph dolomite. All the core samples have been dried and vacuumed to remove any liquid or gas particles present inside.

\section{Core flooding procedure}

The effect of acids on different types of core samples can be represented by acid core flooding technique. Acid-mineral interaction is a complex phenomenon during linear core flooding experiments. Performing linear core flooding acidizing in the laboratory is quite useful to understand the complex acid-mineral interaction process especially in matrix acidizing. The injection rate, fluid and rock properties affect the structure of wormholes (Fredd et al. 1997). A complete dissolution of wormhole structure can occur at the inlet face at low injection rates, i.e., less than $2 \mathrm{ml} / \mathrm{min}$,

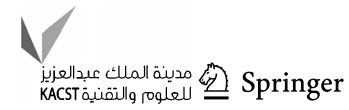




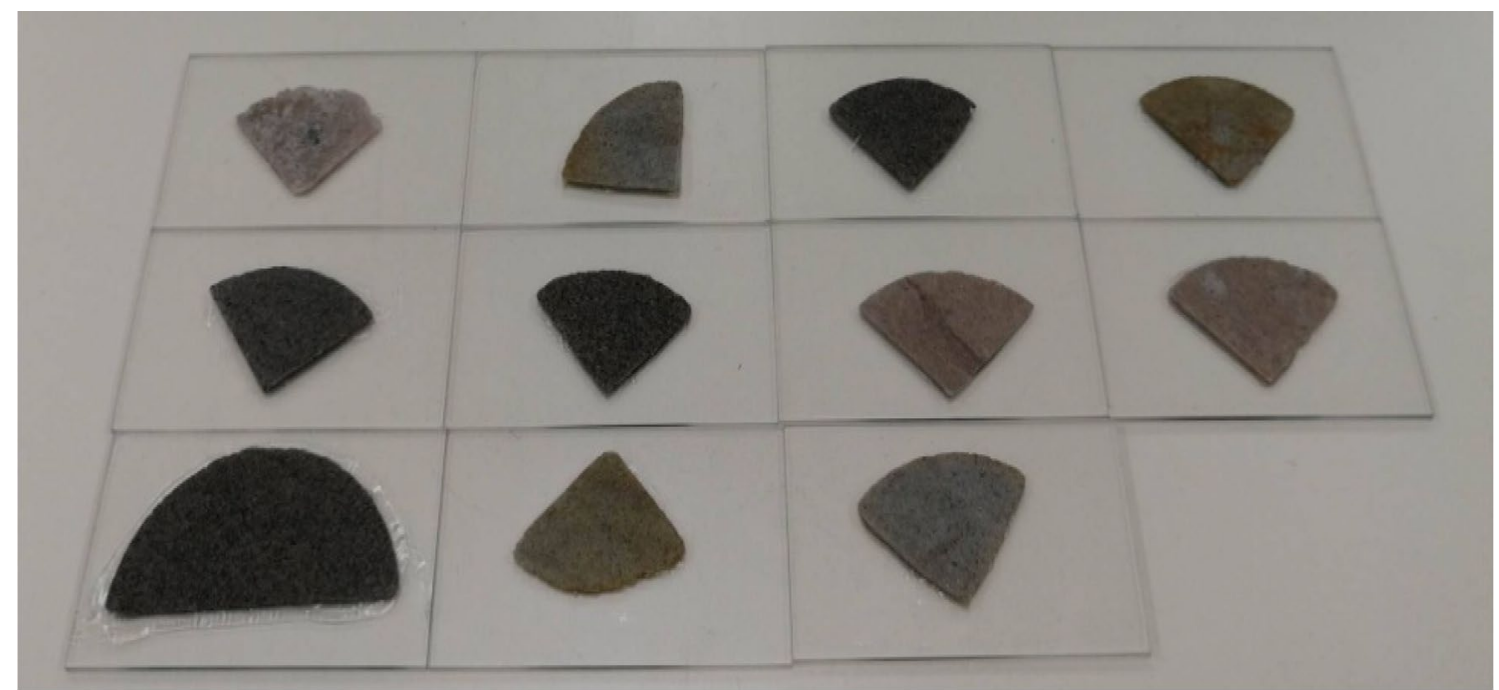

Fig. 2 Core samples prepared for wettability analysis

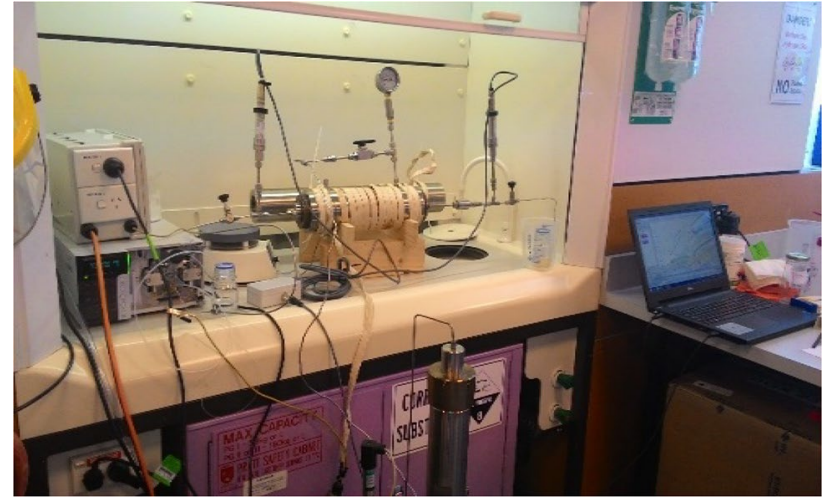

Fig. 3 Core flood setup

while uniform dissolution may occur at higher flow rates and intermediate flow rates may create a single a dominant wormhole. Thus, it is important to monitor the pressure behavior until severe pressure drop can be observed and hence the breakthrough is reached. Therefore, it is necessary to closely monitor the pressure behavior, as sudden pressure drop can be seen which indicates the breakthrough.

After the type of rock and treatment fluids' characteristics are defined along with the requirement of setups, the beakers are filled with appropriate fluids, and then the core flooding can be carried out. The core flooding setup is shown in Fig. 3. The detailed procedure of whole core flooding is as follows:

- The core is inserted inside the core sleeve and placed inside the core holder. Then the inlet and outlet wings of the core holder are closed. The flow lines from the inlet, outlet and high-performance liquid chromatography pump (HPLC pump) are connected. It should be made sure that all the connections between inlet, outlet, pump and core holder are tightened and valves are placed in proper positions. The inlet flow line is connected to the HPLC pump to inject the fluids into the core sample. The flow rate is set at $1 \mathrm{cc} / \mathrm{min}$ and $950 \mathrm{psi}$; the pressure range is selected to disconnect the injected flow of acid.

- The core holder is filled with the water with the help of a syringe pump. The same syringe pump is connected carefully to pressurize the confined core sample. The confining pressure is set at $1000 \mathrm{psi}$. Then the discharge valve of the syringe pump is opened and is filled with water to confine the core sample. The front panel of the syringe pump is used to select the pressure value and flow rate of the water.

- Core holder is wrapped with the heating tape completely, and the temperature controller is connected to the heating tape. The heating tape only starts operation after the core sample is confined under pressure. The pressure and temperature are monitored constantly. The syringe pump is kept connected, and the valve is kept open during heating of the core holder as the increase in temperature can cause the fluid expansion. The temperature of core flooding experiments is set at $80^{\circ} \mathrm{C}\left(180^{\circ} \mathrm{F}\right)$. The core sample and confining fluid inside the core holder are heated for $24 \mathrm{~h}$ before starting the acid injection. This is done to make sure that the whole system should attain the same temperature of $180^{\circ} \mathrm{F}$. The acid is heated to the temperature of $180^{\circ} \mathrm{F}$ with the help of magnetic stirrer and heater before injection, to make sure there is no temperature difference between the acid and the core sample. 


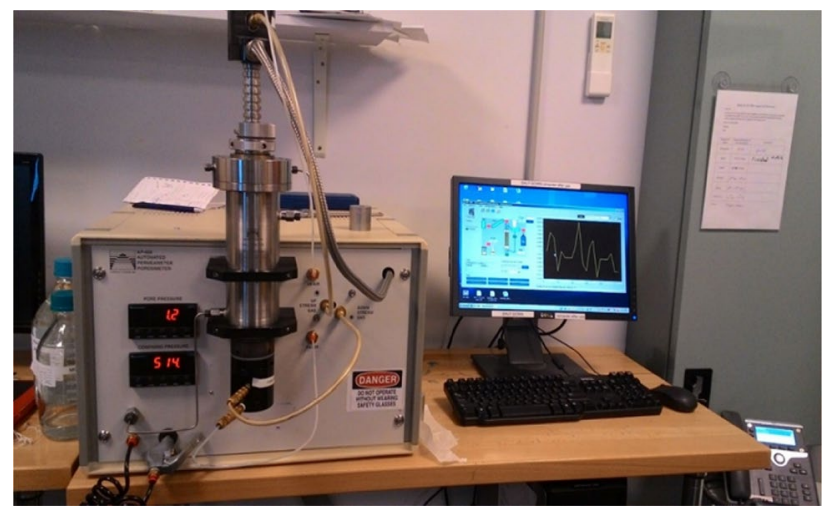

Fig. 4 Automated permeameter-porosimeter

- Pressure transducers are connected with the data acquisition system. The pressure transducers monitor the pressure values at both the inlet and outlet of the core sample.

- The inlet and outlet valves are kept open to allow the fluids to be displaced through the core and collected at the outlet. Once confined and heated, the core flooding experiments are started.

- The pore volume injected and the change in the volume in injection beaker is kept noted once the reacted fluid starts to come out of the outlet flow line. It is made sure that there is no leakage in the flow lines where high pressure was applied.

- The acid flow continued until the constant pressure drop is observed which indicated the completion of the reaction.

- Once the reaction is completed, chelating agent flow is stopped and the water post-flush injection starts to remove the unwanted reaction products.

- When the post-flush with water is finished, HPLC pump is switched off and the inlet valve is closed. When no flow is coming out of the outlet line, confining pressure is released.

- After the completion of the core flooding, all the fittings are disconnected and the core is taken out. All the fittings and the parts of the core holder are rinsed with the distilled water, and the core samples are placed in an oven at $80{ }^{\circ} \mathrm{C}$ for $24 \mathrm{~h}$ to dry.

\section{Results and analysis}

\section{Porosity and permeability analysis}

The porosity is one of the most important properties of reservoir rock where it represents the storage capacity. The permeability is defined as the capacity of the rock to conduct the fluid through its matrix. These properties are very important for understanding/estimating the oil and gas initially in place and the ability of the rock to transmit a fluid. The porosity can be determined by applying certain techniques like saturation method or determination using automatic porosity analysis apparatus. In this research, porosity and permeability are measured before and after core flooding experiments using the automated permeameter-porosimeter (AP-608) from Coretest system Inc. as shown in Fig. 4. AP-608 instrument is cost-effective and applied Boyle's law to measure the porosity and Klinkenberg effect to measure the permeability.

Helium gas is a non-toxic and non-damaging gas to the core samples, and because of its high diffusivity, it is used as the pore fluid to measure porosity and permeability. Klinkenberg-corrected permeability can be measured using AP-608 systems. Using automated permeameter-porosimeter, porosity can be calculated at different confining pressure ranges. During this research, the porosity values at confining pressure of 1000 psi are measured because the confining pressure during the core flooding experiments was $1000 \mathrm{psi}$ maximum. The permeability measured range is $0.001 \mathrm{mD}$ to $>10$, depending on the sample, while the porosity range is 0.1 to $>40 \%$. Along with the porosity and permeability, the pore volume of each core sample was also measured as an important parameter to determine the breakthrough and used to understand the reaction completion. This apparatus can be used to carry out measurements up to 9550 psi pressure.

Dissolution of calcium, sodium, magnesium, iron, silicon and potassium ions present in the core sample is the main target of injecting acids during sandstone acidizing. By dissolving these ions new pores will be created while contributing little toward permeability, because these ions are only contributing a very small amount of the bulk minerals present inside the core. So, a change in porosity can be observed, while the change in permeability can be negligible as the pores created will be capillary pores. Usually, sandstone samples contain very less amount of these positive ions, except silicon which is the major element in a sandstone formation. But acids can only dissolve a small amount of silicon; therefore, as a result, the change in porosity is also less. These positive ions should be removed before injecting the main acid to avoid precipitation reactions.

Table 3 represents the change in porosity and permeability before and after core flooding experiments. HEDTA was found to be very effective in increasing the permeability and porosity in all samples tested. The major difference was analyzed in terms of permeability increment in tight sandstone and dolomite formations, where HEDTA managed to increase the permeability of tight sandstone and dolomite by $105 \%$ ( 2 times the original) and $85 \%$, respectively, while other chelates were not effective. EDTA and GLDA manage to increase the porosity by good amount, but less permeability increment is observed which can be due to the reaction products formed inside and blocking of the paths of

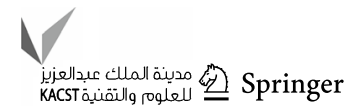


Table 3 Porosity $(\varnothing)$ and permeability $(K)$ results

\begin{tabular}{|c|c|c|c|c|c|c|c|}
\hline Sample name & Chelate & Initial porosity (\%) & $\begin{array}{l}\text { Final poros- } \\
\text { ity }(\%)\end{array}$ & $\%$ Change & Initial $K$ (md) & Final $K(\mathrm{md})$ & $\%$ Change \\
\hline Colton sandstone 1 & EDTA & 10.74 & 11.66 & 8.5 & 0.7118 & 0.7379 & 3.6 \\
\hline Colton sandstone 1 & HEDTA & 11.49 & 12.65 & 10.10 & 0.4633 & 0.9542 & 105 \\
\hline Colton sandstone 1 & GLDA & 12.13 & 13.01 & 7.25 & 0.8069 & 0.8542 & 5.8 \\
\hline Dolomite 1 & EDTA & 16.80 & 16.82 & 0.11 & 104.27 & 108.72 & 4.2 \\
\hline Dolomite 1 & HEDTA & 14.19 & 15.09 & 6.3 & 9.80 & 18.11 & 85 \\
\hline Dolomite 1 & GLDA & 21.20 & 21.63 & 2.03 & 405.55 & 425.41 & 4.9 \\
\hline Berea sandstone 1 & EDTA & 19.04 & 20.01 & 5.09 & 124.53 & 128.35 & 3 \\
\hline Berea sandstone 1 & HEDTA & 19.705 & 21.04 & 6.77 & 165.21 & 166.34 & 0.7 \\
\hline Berea sandstone 1 & GLDA & 19.06 & 20.09 & 5.4 & 80.41 & 84.93 & 5.6 \\
\hline
\end{tabular}
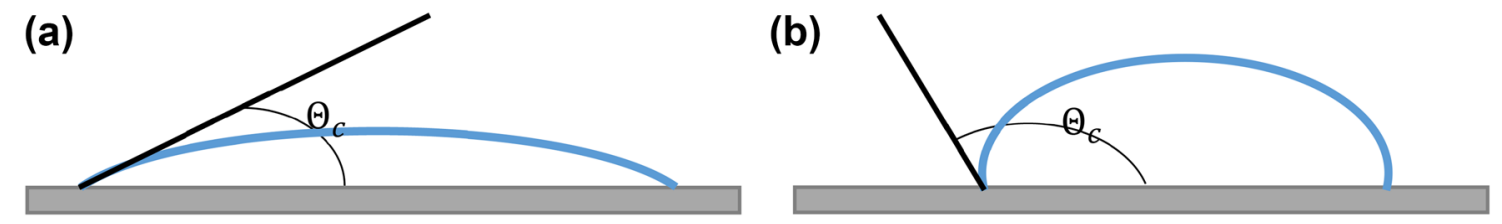

Fig. 5 Contact angles of a water-wet surface and b oil-wet surface (Alotaibi et al. 2011)

flow. Also, the dolomite sample is heterogeneous and permeability value is higher than $100 \mathrm{md}$. According to (Alotaibi et al. 2011), if the permeability is more than $100 \mathrm{md}$, the acidizing job is not effective. Also, if we compare the results of permeability by application of GLDA and EDTA on Colton sandstone and Guelph dolomite, almost similar trend is observed, where permeability is increased by $3.6 \%$ and $4.2 \%$ when EDTA is applied on tight sandstone and dolomite, respectively, while permeability is increased by $5.8 \%$ and $4.9 \%$ when GLDA is applied on tight sandstone and dolomite, respectively. These results can be further validated using NMR analysis where a change in porosity and pore size distribution can be analyzed.

\section{Wettability test}

Wettability is the ability of the fluid to cover the surface area of the rock sample. Wettability test can be performed to recognize the wetting behavior of fluids (oil and water), on the rock surface. Wettability is usually determined with the help of a contact angle measured through the denser/water phase. Figure 5 illustrates the water-wet and oil-wet conditions and their corresponding contact angles $\Theta_{c}$.

The contact angle of liquid (water) with a rock in the range of $0^{\circ}-75^{\circ}$ usually represents water-wetting conditions, while $115^{\circ}-180^{\circ}$ indicates oil-wetting conditions. On the other hand, the angle from $75^{\circ}$ to $115^{\circ}$ indicates neutral wettability, which shows that the rock surface is neither wetted by oil nor by water (Alotaibi et al. 2011). The ability of the wetting phase to stick to the rock surface and inhabit/ occupy the smaller pore spaces within the reservoir is due to the capillary pressure inside the rock. Consequently, the wetting phase has lower mobility due to its trapping inside the small pores (low-permeability channels) as compared to the non-wetting phase. Therefore, the non-wetting phase was produced easily/faster compared to the wetting phase. However, in the case of a tight reservoir, the fluid used for stimulation like an acid usually traps and accumulates in the small pore throats of the reservoir due to high capillarity. This can be the reason for the blocking of the hydrocarbons flow path and water banking. The hydrocarbons must overcome this very high capillary pressure (capillary effect) created by the blocking of fluids which in turn can considerably reduce the production of hydrocarbon, most importantly gas (Saneifar et al. 2010, 2011). Thus, wettability conditions are different in different reservoirs based on reservoir conditions and enhanced oil recovery (EOR) techniques applied (Mohammadi et al. 2009). In conventional sandstone reservoirs, usually water-wet conditions are favorable to optimize the production of hydrocarbons. In this project, the wettability of the different core samples has been measured by recording the contact angles from the Drop Shape Analyzer (DSA) apparatus. The DSA is equipped with aperture, illumination, sample table, prism, dosing unit and camera. The liquid was dropped by the dosing unit which was then detected by the camera. Later, the image was sent to the computer for further analysis. Then, the contact angle of that drop of liquid was interpreted, generated and analyzed. 
Table 4 Contact angles of the core samples

\begin{tabular}{ll}
\hline Core samples & $\begin{array}{l}\text { Contact } \\
\text { angles, } \Theta_{\mathrm{c}} \\
\left({ }^{\circ}\right)\end{array}$ \\
\hline Dolomite A (EDTA) & 87.55 \\
Dolomite B (HEDTA) & 83.89 \\
Dolomite C (GLDA) & 83.75 \\
Berea A (EDTA) & 69.92 \\
Berea B (HEDTA) & 62.86 \\
Berea C (GLDA) & 60.95 \\
Berea E (initial) & 71.94 \\
Colton A (EDTA) & 76.54 \\
Colton B (HEDTA) & 73.90 \\
Colton C (GLDA) & 73.42 \\
Colton E (initial) & 78.74 \\
\hline
\end{tabular}

The results are mentioned in Table 4. Drop Shape Analyzer is shown in Fig. 6.

\section{Procedure}

Once the instrument was switched on, all the necessary information was entered using the ADVANCE software, under the text boxes of NAME and DETAILS. Also, the temperature range was entered in the software at which the experiment was carried out. Then, the liquid used by the dosing unit was selected (distilled water in this case) under the section CONFIGURE DOSING, and afterward, the syringe was filled with that liquid. Later, a thin section of the core sample was placed beneath the syringe and calibration was performed on ADVANCE software. After calibration, a drop of brine was put on the core sample placed and the contact angle was recorded by using the ADVANCE software.

The details and results are given in Table 4, which shows that the change in wettability of Berea sandstone samples shifts toward more water-wet conditions, which is favorable for the oil and gas production. The initial contact angle of Berea sandstone core sample was 71.94, nearly neutral wetting conditions. But after reacting with the chelating agents, the contact angle decreased to 69.92 in case of EDTA $(2.8 \%$

Fig. 6 Drop Shape Analyzer (DSA100)
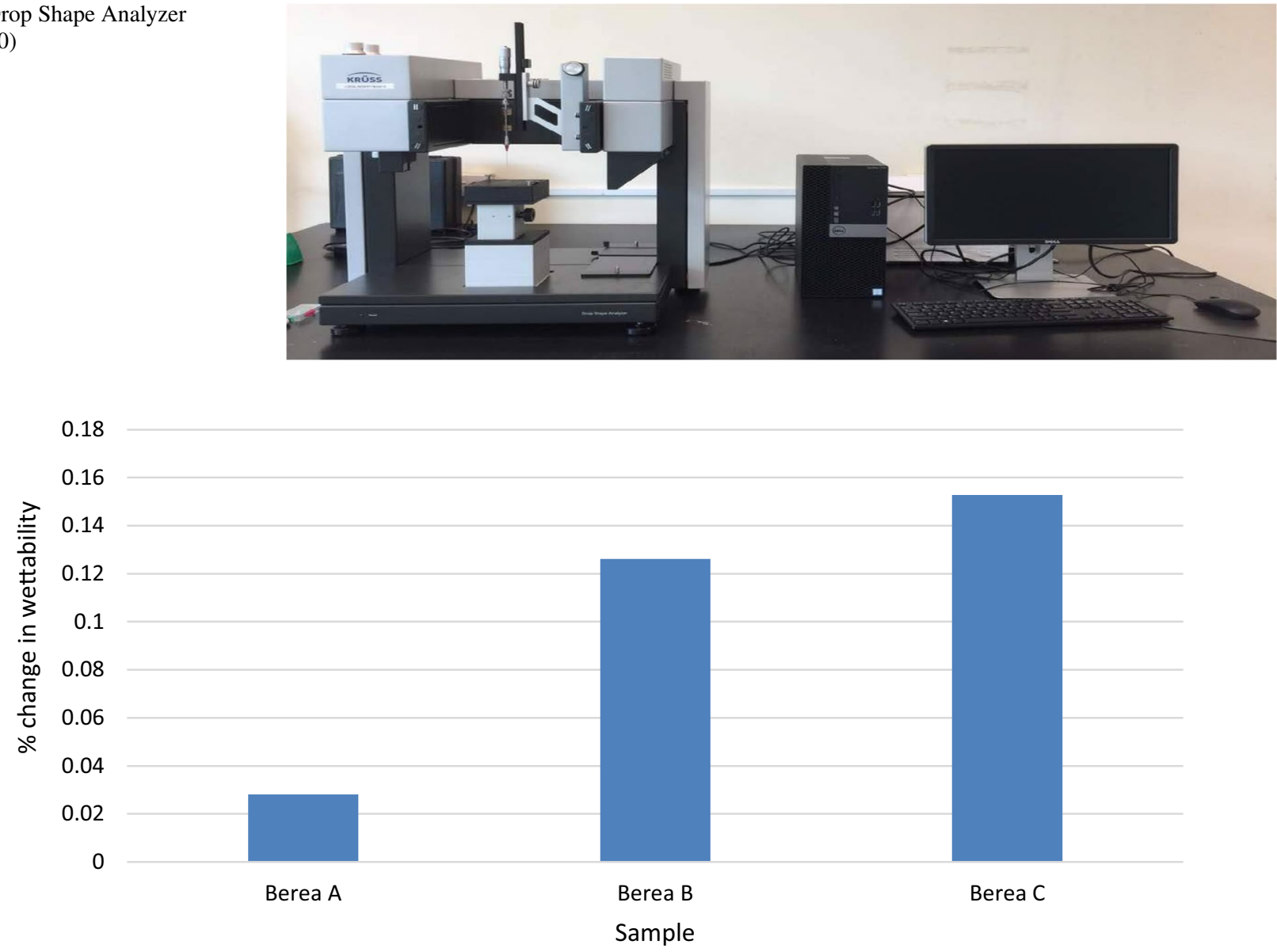

Fig. 7 Wettability changes in Berea sandstone after acidizing 


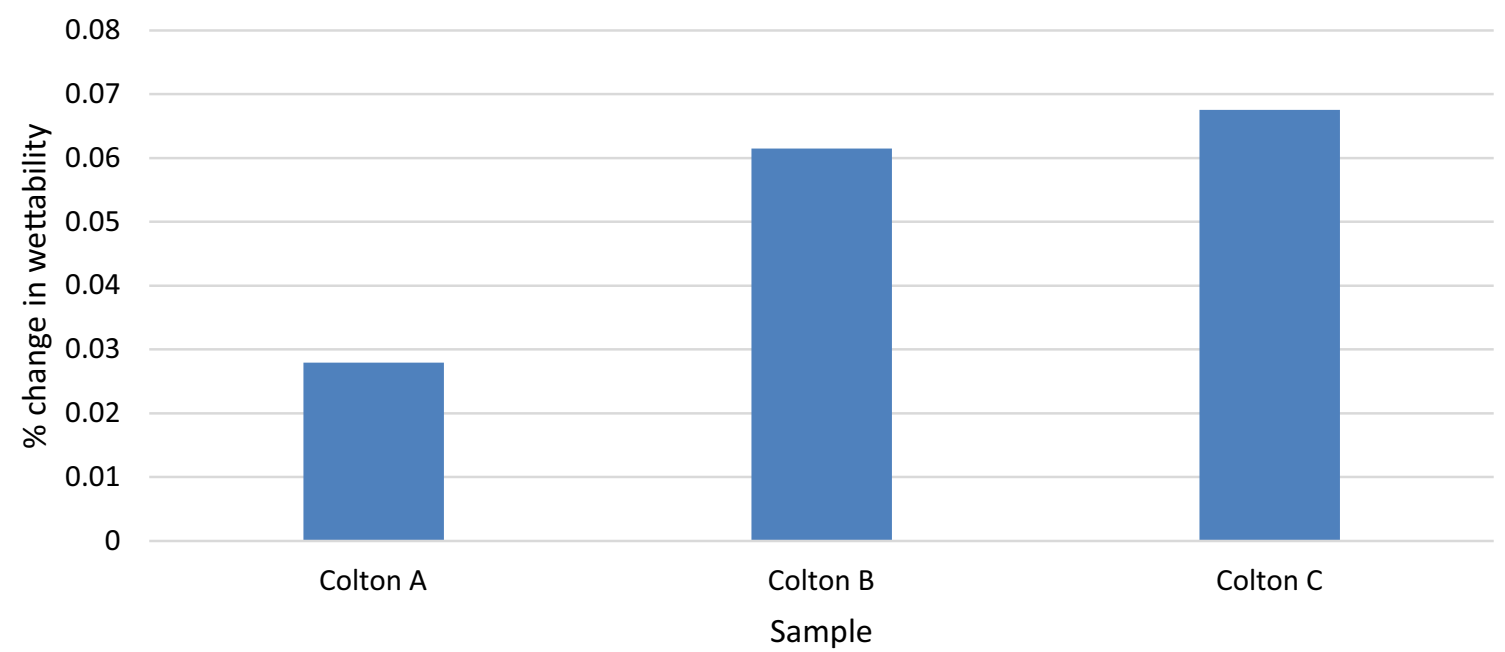

Fig. 8 Wettability changes in Colton sandstone after acidizing

change), 62.86 in case of HEDTA (12.6\% change) and 60.95 in case of GLDA (15.3\% change) as shown in Fig. 7.

As seen from Table 4, the change in wettability of Colton sandstone samples shifted toward more water-wet conditions, which is favorable for the oil and gas production. The initial contact angle of Colton sandstone core sample was 78.74 , neutral wetting conditions. But after reacting with the chelating agents, the contact angle decreased to 76.54 in case of EDTA (2.7\% change), 73.90 in case of HEDTA (6.1\% change) and 73.42 in case of GLDA (6.7\% change) as mentioned in Fig. 8. From the analysis of sandstone sample, one trend is very clear where the maximum change in wettability was observed when GLDA reacted with sandstone formation. On the other hand, the minimum change in wettability was observed when the core sample reacted with EDTA. A similar trend has been observed in case of dolomite samples also, where the contact angle value is toward the higher side when reacted with EDTA compared to other chelates where the contact angle has decreased and shifted toward water-wet conditions as seen in Table 4. Therefore, chelating agents are not only increasing the permeability and porosity of the reservoirs but also change the wettability of the sandstone core sample. From Table 4, it is observed that the potential change in the wettability of the reservoir rock shifted toward more water-wet condition. Therefore, this wettability change can increase the imbibition of water into the hydrocarbon reservoir, consequently optimizing the oil recovery (Xu et al. 2008). This change in wettability is due to the fact that chelating agents dissolve minerals present inside the pore spaces as described by (Shafiq et al. 2018).

Wettability analysis was not performed during the preflush stage because the acid does not affect the wettability of core samples. The results are verified by the experimental work carried out by (Saneifar et al. 2010). In this work they
Table 5 Pore volume of core samples before and after acidizing

\begin{tabular}{lllll}
\hline Sample & Description & $\begin{array}{l}\text { Initial pore } \\
\text { volume } \\
(\mathrm{ml})\end{array}$ & $\begin{array}{l}\text { Final pore } \\
\text { volume } \\
(\mathrm{ml})\end{array}$ & \% Change \\
\hline Colton & Sample A & 8.908 & 9.827 & 0.103166 \\
& Sample B & 9.66 & 10.709 & 0.108592 \\
& Sample C & 10.193 & 11.052 & 0.084274 \\
Dolomite & Sample A & 14.155 & 14.292 & 0.009679 \\
& Sample B & 12.101 & 12.637 & 0.044294 \\
& Sample C & 18.057 & 18.336 & 0.015451 \\
Berea (group 2) & Sample A & 16.98 & 17.708 & 0.042874 \\
& Sample B & 16.19 & 17.096 & 0.05596 \\
& Sample C & 16.28 & 17.19 & 0.055897 \\
\hline
\end{tabular}

showed that the $15 \% \mathrm{HCl}$ spent acid did not significantly affect the wettability of the core samples. They also investigated that increasing or decreasing the concentration of acid also did not affect the wettability of the formation.

\section{Solubility and pore volume analysis}

The solubility test describes the dissolving power of the chelating agent or acid during acidizing. This test can be used to validate the porosity and permeability analysis discussed earlier. On the other hand, the pore volume measurement can investigate the volume of acid or chelate required for the acidizing. As the flow rate is constant for all the tests $\left(1 \mathrm{~cm}^{3} / \mathrm{min}\right)$ and the total volume to be injected is also constant for all samples-15 pore volume (15 PV)-pore volume analysis on the one hand can investigate the volume of acid required, while change in pore volume after acidizing can validate porosity analysis discussed earlier. Tables 5 and 
Table 6 Weight of core samples before and after acidizing

\begin{tabular}{lllll}
\hline Sample & Description & $\begin{array}{l}\text { Initial weight } \\
(\mathrm{g})\end{array}$ & $\begin{array}{l}\text { Final weight } \\
(\mathrm{g})\end{array}$ & \% Change \\
\hline Colton & Sample A & 202.1 & 200.8 & 0.006432 \\
& Sample B & 199.7 & 196.1 & 0.018027 \\
& Sample C & 197.7 & 196.528 & 0.005928 \\
Dolomite & Sample A & 200.3 & 199.8 & 0.002496 \\
& Sample B & 207.1 & 203.4 & 0.017866 \\
& Sample C & 190.1 & 188.13 & 0.010363 \\
Berea & Sample A & 178.27 & 177.12 & 0.006451 \\
& Sample B & 176.64 & 174.64 & 0.011322 \\
& Sample C & 180.71 & 179.87 & 0.004648 \\
\hline
\end{tabular}

6 represent the pore volume and weight changes, respectively, of all the core samples after acidizing.

It has been observed that the maximum pore volume increment is created by $5 \% \mathrm{CH}_{3} \mathrm{COOH}: 10 \% \mathrm{HCl}$ in case of Berea sandstone (5.9\%), by HEDTA in Colton sandstone $(10.85 \%)$, by HEDTA in dolomite $(5.6 \%)$ and by HEDTA in
Berea sandstone (5.6\%). These changes validate the porosity and permeability analysis discussed in earlier sections.

Table 6 represents the change in the dry weight of the core sample before and after acidizing. The maximum decrease in the weight of Berea sandstone, Colton sandstone and Guelph dolomite has been observed when they were reacted with HEDTA (1.1, 1.8 and 1.7\% decrement, respectively). Likewise, the maximum decrement has been observed when Berea sandstone reacted with $5 \%$ $\mathrm{CH}_{3} \mathrm{COOH}: 10 \% \mathrm{HCl}$, hence validating porosity, permeability and pore volume analysis.

\section{CT scan analysis}

The cores were photographed and re-weighted after the core flooding experiments were finished, to determine the wormhole creation and weight loss. The weight loss is already discussed in Table 6, while photographed cores with wormholes can be seen in Fig. 9a-d. Figure 9a shows the core sample inlet face before acidizing. On the other hand, Fig. 9b-d shows the core samples inlet face after acidizing with GLDA, HEDTA and EDTA, respectively. All the
Fig. 9 Photographed dolomite core samples and creation of wormholes
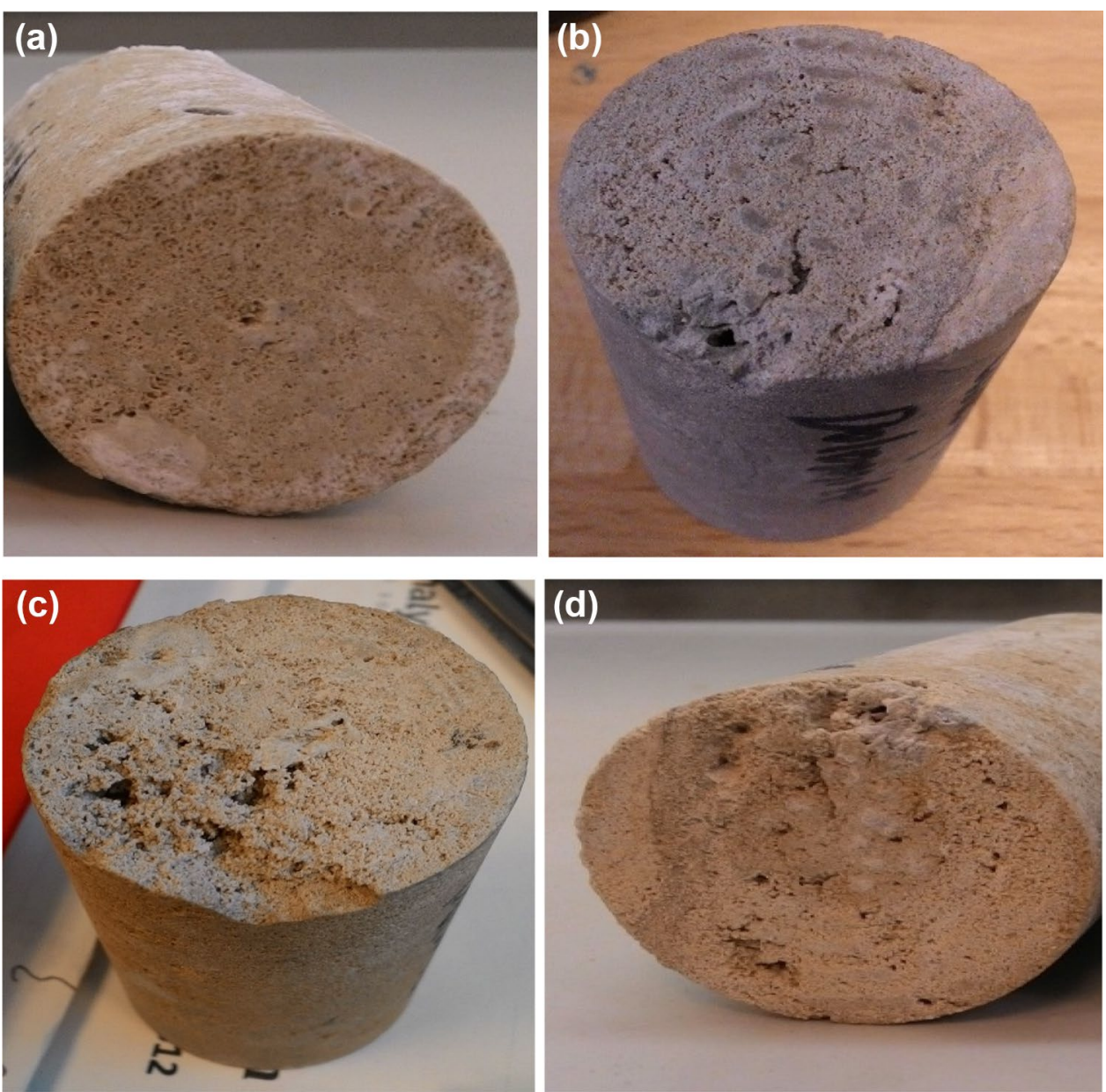
chelating agents successfully created new wormholes in the dolomite core samples. However, face dissolution was maximum in case of HEDTA (Fig. 9c) compared to other chelates. That is why the change in porosity and permeability when dolomite sample reacted with HEDTA was a maximum. It is worth noting that good wormhole structures are usually formed in the carbonate samples compared to the sandstone samples because of the presence of more than $90 \%$ silica in sandstone which is not soluble by the chelates. Therefore, Fig. 9a-d only shows dolomite core samples as no wormhole structure has been observed in sandstone samples.

To further investigate the pore structure of the core samples, micro-CT scan analysis were conducted on a small section of core samples $(6 \mathrm{~mm} \times 8 \mathrm{~mm})$ reacted with HEDTA. Micro-CT scan is just like X-ray vision but with better resolution. Without destroying the subject it allows seeing inside of the subject. It is just like a medical CT system where one can get slice-by-slice images without destroying the sample (Carlson 2006). 2D images tell us what is in the object, but 3D images obtained using micro-CT can tell us where those things are present inside the object.

\section{A broad overview of micro-CT}

Micro-computed tomography is a technique in which X-rays are emitted from an X-ray generator. These X-rays travel through the sample and on the other side are recorded by a detector to produce a radiograph also known as a projection image. Then another projection image at a new position will be taken by rotating the sample by a fraction of a degree. Series of projection images have been taken by rotating the sample by 180 or 360 degrees with continuous iterations. One of the major advantages of CT scan technique is that it can characterize the three-dimensional rock internal structure without destroying it. It can provide a stack of 1000 or more 2D cross-sectional images of the investigated sample nondestructively, which is much faster than performing serial sectioning. On the contrary, only small samples can be analyzed using this technique which therefore required many samples to be scanned to get the correct volume. To determine the properties like electrical conductivity and permeability, the complex internal microstructure needs to be described properly. X-ray micro-tomography is very useful but is not readily available, and 2D thin sections are the most adequate source of information for pore structure analysis (Øren and Bakke (2002). Accordingly, the most appropriate approach was to make a 3D structure from already available 2D images by using statistical models (Joshi 1974; Adler et al. 1990, 1992; Hazlett 1997; Yeong and Torquato 1998a, b). However, in the beginning, the CT scan was mostly applied for medical purposes, but soon it was realized that it had good potential in many other fields and applications like paleontology (Fourie 1974), soil science (Allan et al. 2002) and fluid flow research (Wellington and Vinegar 1987). Image analysis of 3D structure starts with high-quality images, because it is useful to get valuable information from the true images. Image analysis usually consists of complex image processing and advanced calculations (Starkey and Samantaray 1994). Image analysis consists of a few steps which include noise reduction followed by segmentation and then binary image editing. However, $2 \mathrm{D}$ original images need to be processed before performing image analysis. This image analysis is mainly done in order to enhance the appearance of the images. Figure 10 shows the initial raw image and processed segmented image of one of the core samples used during this research. For each sandstone and dolomite core sample, around 700 2D raw images were obtained, segmented and then converted into a 3D image. The initial 2D sandstone image obtained was very dark and it was very hard to determine the pore spaces, while after image analysis, the quality of image improved a lot as shown in Fig. 10. The segmented image shows different minerals present inside the Berea sandstone core sample represented by different numbers in Fig. 10, while the segmented image of dolomite core sample mostly shows ankerite mineral which is around $97 \%$ of the total matrix. In both segmented images shown in Fig. 10, the blue color represents the pore spaces.

Figure 11 shows the pore structure of sandstone and dolomite core samples, respectively, before and after the acidizing procedure. These samples are reacted with HEDTA chelate, and porosity of 3D core samples has been calculated for each sample. An increase in the pore spaces has been observed in both cases, and porosity for sandstone sample changed from 13.96 to $17.20 \%$, while for carbonate the porosity increased from 8.66 to $10.93 \%$.

\section{NMR analysis}

The porosity measured by NMR tools can be divided into two components: pores reflecting free fluid index (FFI, associated with large pores/connected pores), and bulk volume irreducible (BVI) associated with capillary pores (Fig. 12). FFI is the amount of porosity associated with fluids that are free to flow (mobile fluid), and BVI is the amount of porosity associated with fluids that will not flow (immobile fluid). An NMR pore size distribution can be used to divide the fluid content into producible fluids (FFI) that are mobile and 

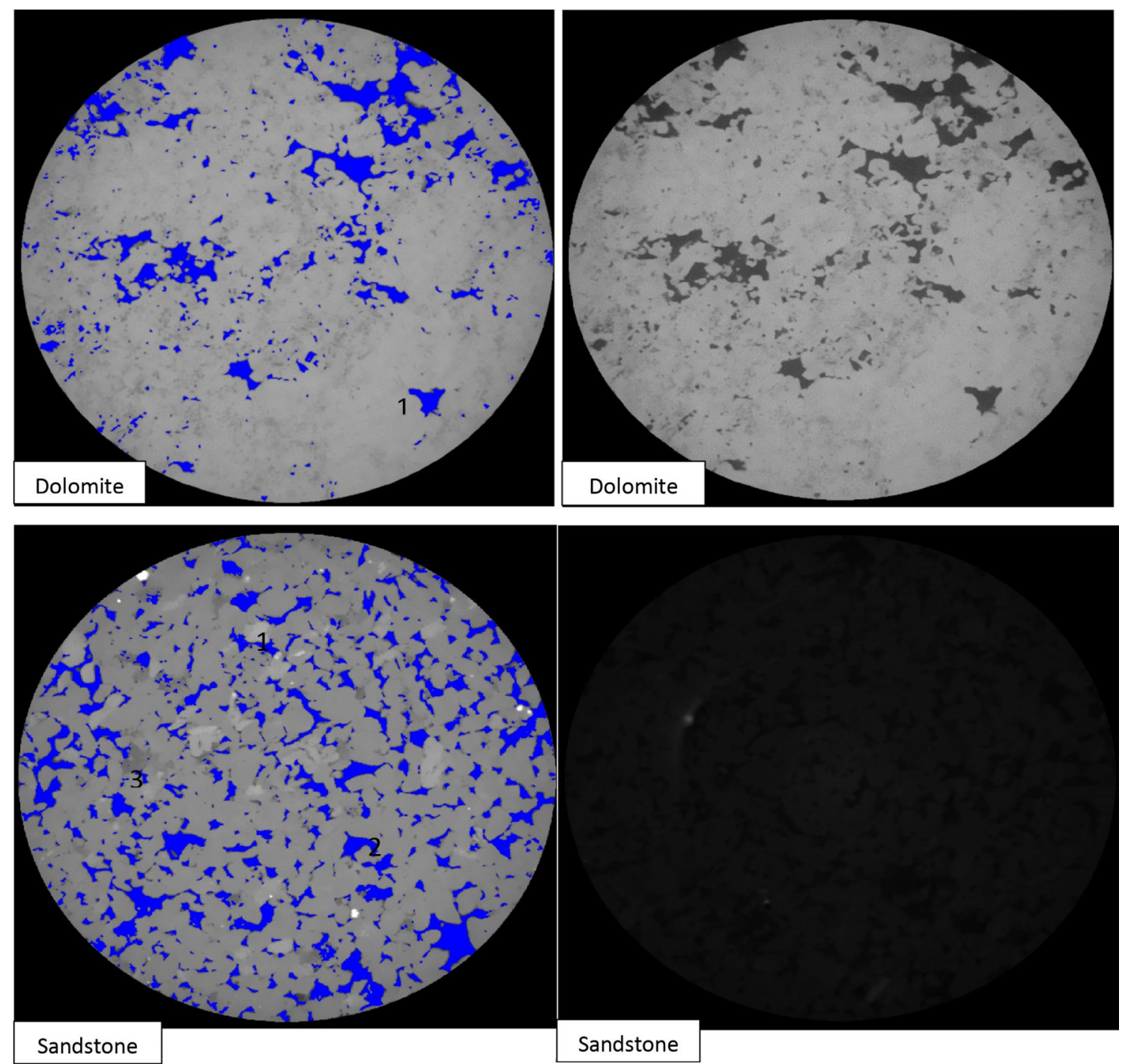

Fig. 10 Dolomite and sandstone formation: (left) segmented images; (right) raw image

capillary bound water fluids that are immobile (BVI). These divisions are made using a relaxation time cutoff.

$\varnothing_{\mathrm{NMR}}=\mathrm{FFI}+\mathrm{BVI}$

\section{Procedure}

Maran-Ultra $2 \mathrm{MHz}$ benchtop spectrometer (a resonance instrument) was utilized to conduct the NMR experiments and analysis. NMR analysis was carried out on almost all the samples which were used during the core flooding procedure. On these samples, the NMR measurements were taken twice (before and after the core flooding experiments). To generate the $\mathrm{T}_{2}$ relaxation time for the samples tested, a hard pulse CPMG sequence was used. Meanwhile, the difference in the porosities and permeabilities of samples used was not much different; a constant combination of parameters was considered acceptable in the generation of $\mathrm{T} 2$ distribution spectrum which represents the pore size distribution inside the core samples. The number of scans (NS) was set at 8 , which is good and can help to produce very high-quality 

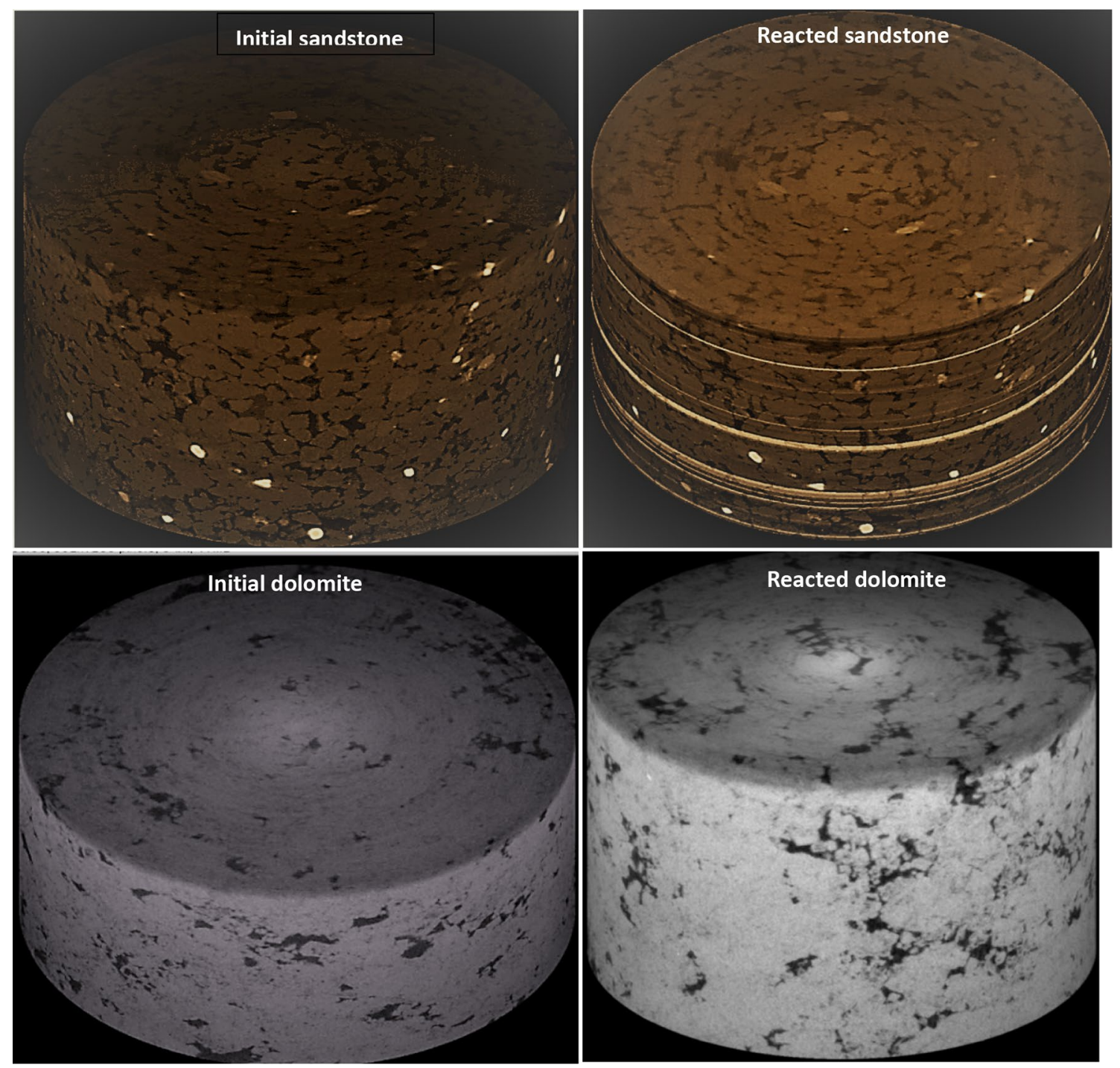

Fig. 11 3D CT scan image of Berea sandstone and Guelph dolomite formation reacted with HEDTA

spectrum by attaining a high signal-to-noise ratio. Relaxation delay (RD) was set at $30 \mathrm{~s}$ which also assures full polarization for precise measurements. Pore size, pore fluid and mineralogy of the formation affect $\mathrm{T} 2$ relaxation time. When T2 time is encountered with the same rock type and the pore filling fluid, the pore size will be the most important parameter to control. The less change in the commulative spectrum of Colton sandstone is observed in samples A and $\mathrm{C}$, validating porosity results. Based on the NMR analysis, pore spaces have been increased for all samples studied. The maximum increase in porosity is for sample B where the porosity is increased from about 12.5 to $14 \%$ (Fig. 13). 
Fig. 12 Dependence of T2 distribution on NMR acquisition parameters (Marschall 2000)
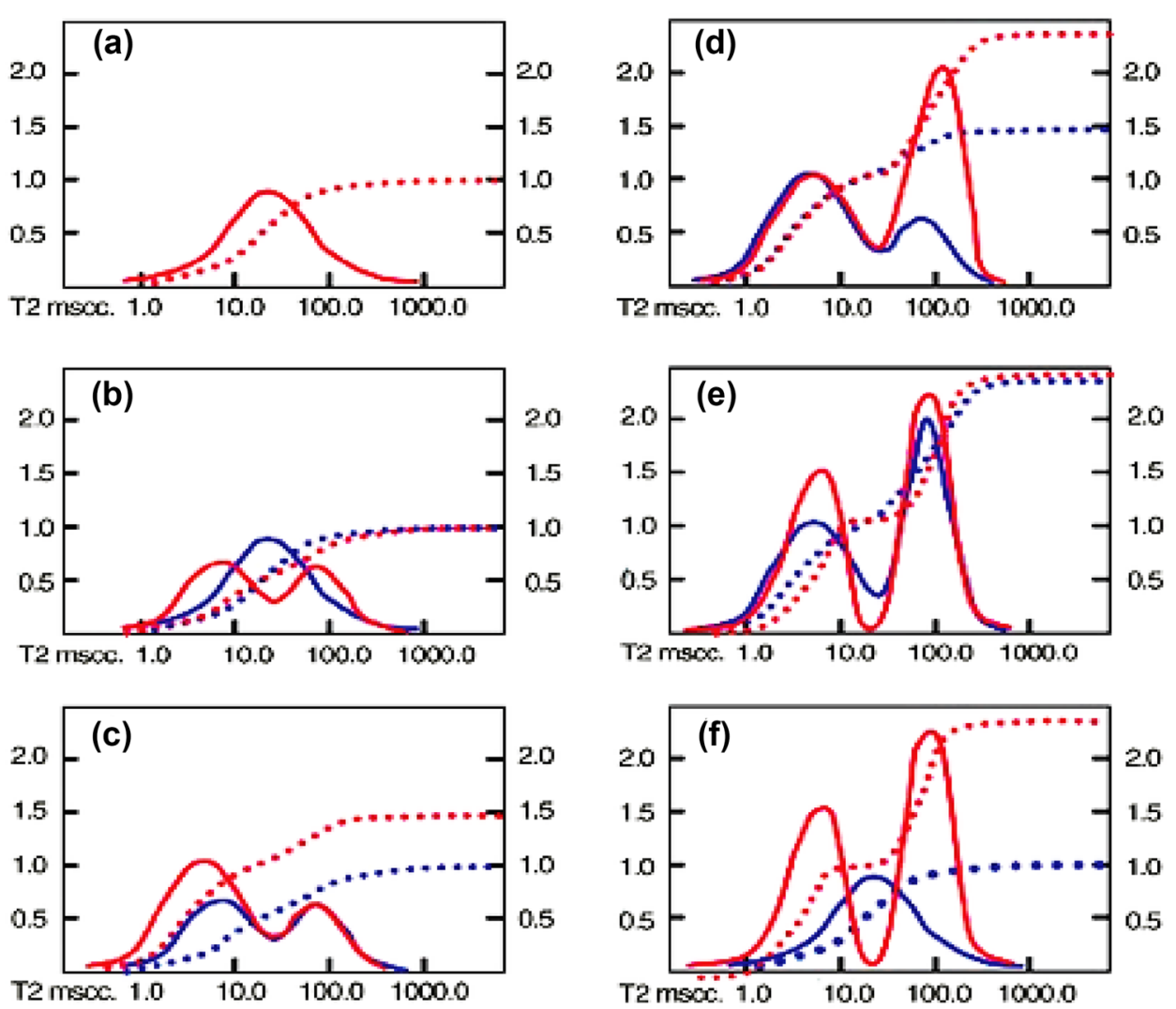

The decrease in the commulative spectrum for Guelph dolomite samples is observed in sample A, validating porosity results. Based on the NMR analysis, pore spaces have been increased for samples $\mathrm{B}$ and $\mathrm{C}$. The maximum increase in porosity is for sample $\mathrm{B}$ where the porosity is increased from about 14.5 to $16 \%$ (Fig. 14).

Based on the NMR analysis, pore spaces have been increased for all Berea sandstone core samples. The maximum increase in porosity is observed in sample B where the porosity increased from about 22 to $24 \%$ (Fig. 15).

The importance of NMR logging in matrix acidizing can be attributed to the ability of NMR logging to determine FFI and BVI. FFI represents the pore spaces where the oil can move, and the main objective or goal of matrix acidizing is to create more pore spaces where oil can move easily. Successful matrix acidizing can increase FFI where if damage occurs during acidizing BVI area will increase. 
Commulative Porosity, Sample A

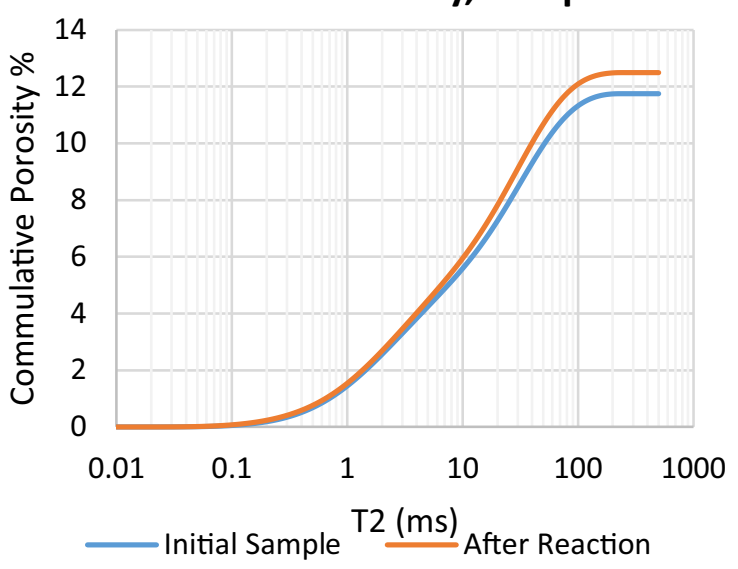

\section{Commulative Porosity, Sample B}

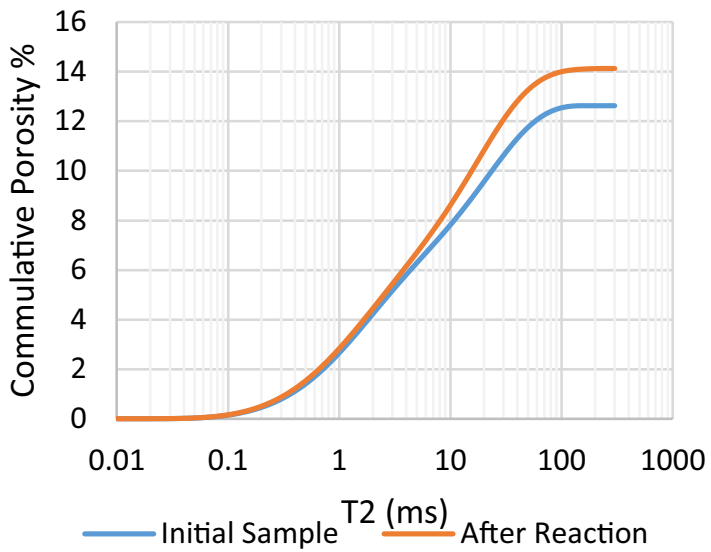

Commulative Porosity, Sample C

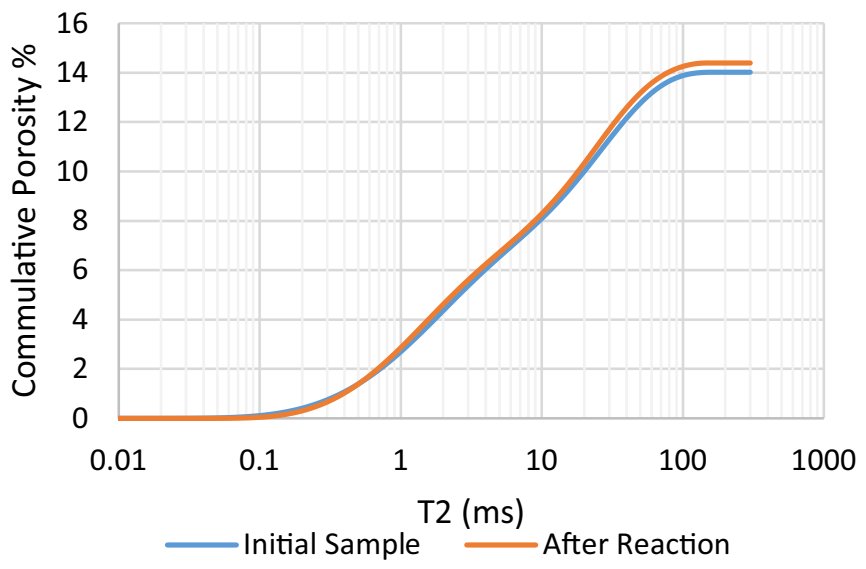

Fig. $13 \mathrm{~T} 2$ commulative spectrum of all Colton sandstone core samples before and after reaction with chelates

\section{Conclusion}

- HEDTA was proved to be effective in increasing permeability and porosity of the tight sandstone and dolomite formations. 


\section{Commulative Porosity, Sample A}

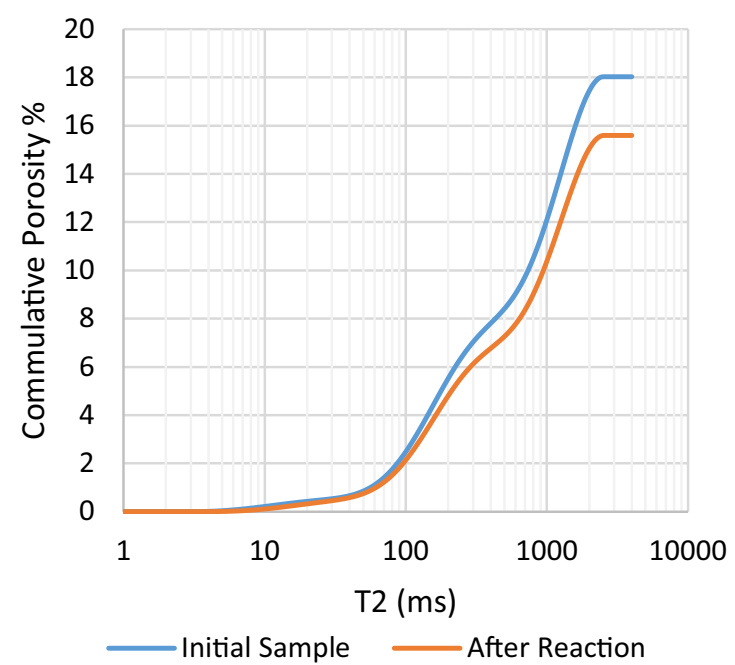

\section{Commulative Porosity, Sample B}

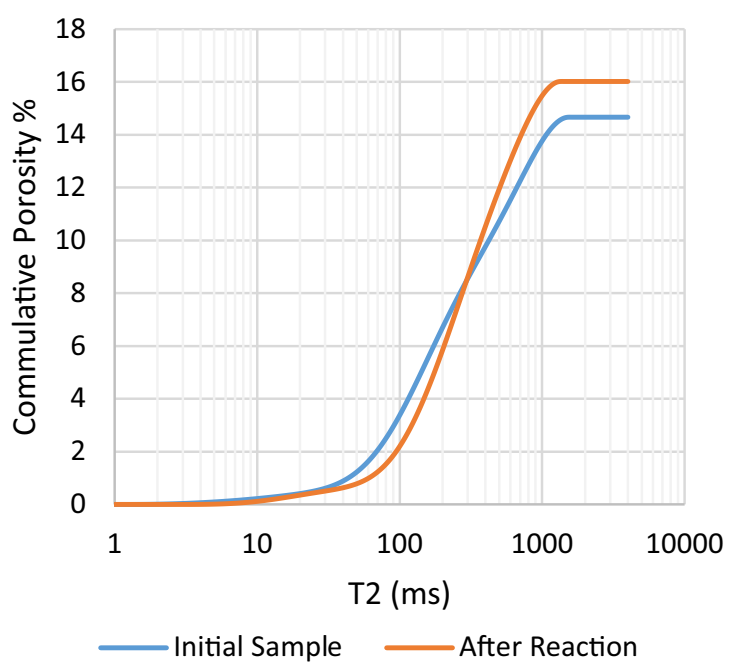

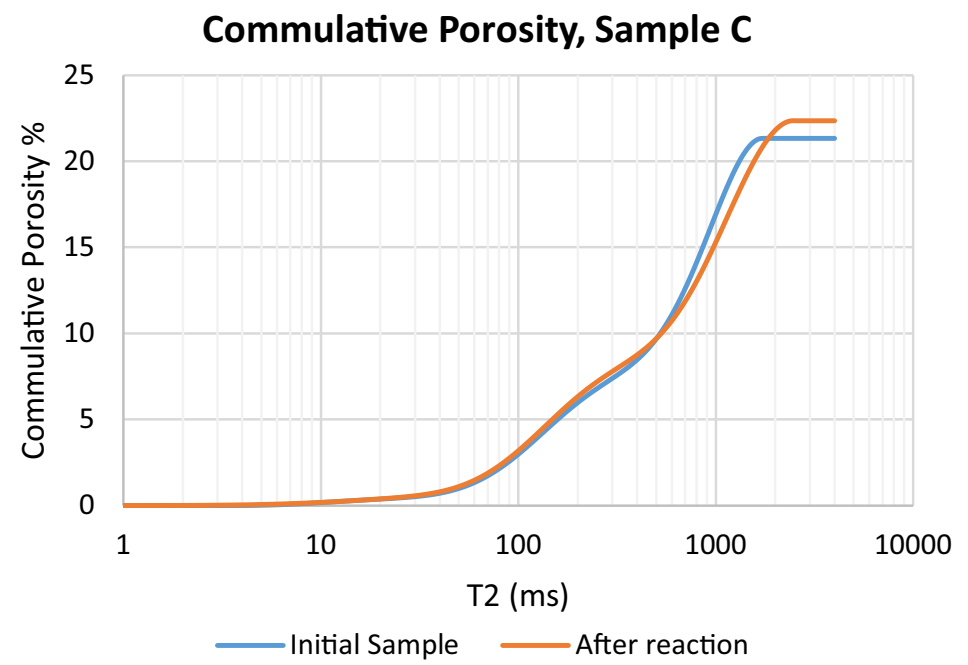

Fig. 14 T2 commulative spectrum of all Guelph dolomite core samples before and after reaction with chelates 


\section{Commulative Porosity, Sample A}

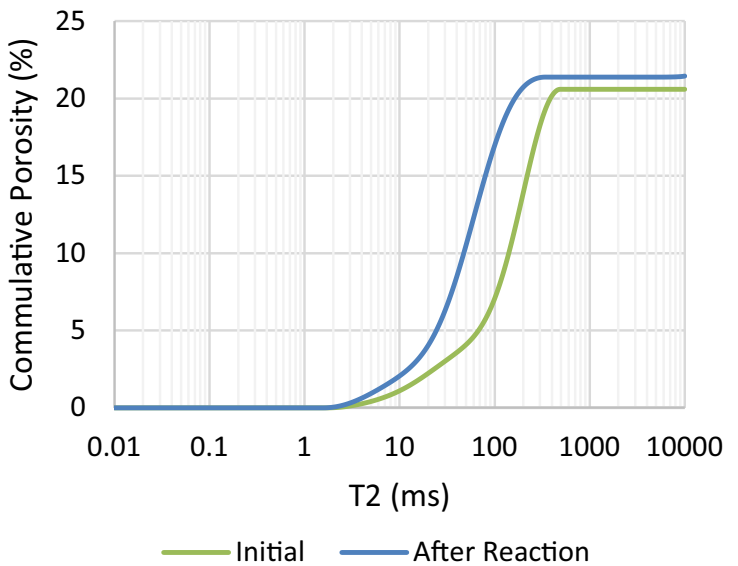

\section{Commulative Porosity, Sample B}

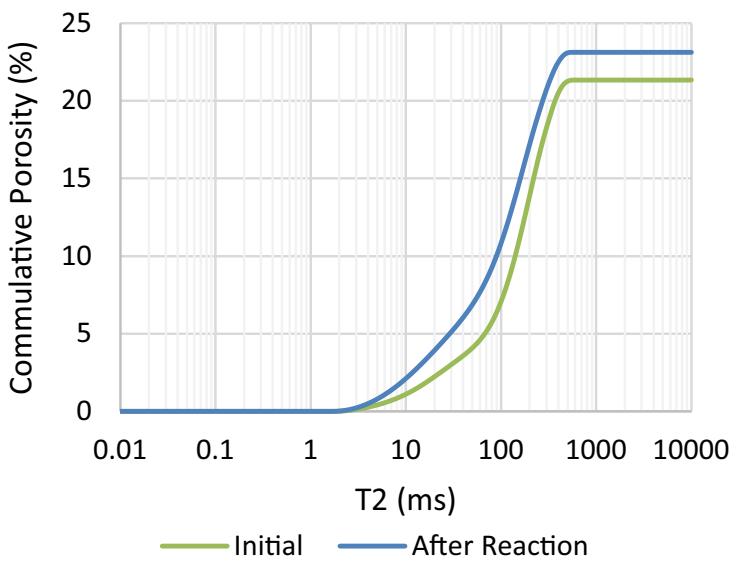

\section{Commulative Porosity, Sample C}

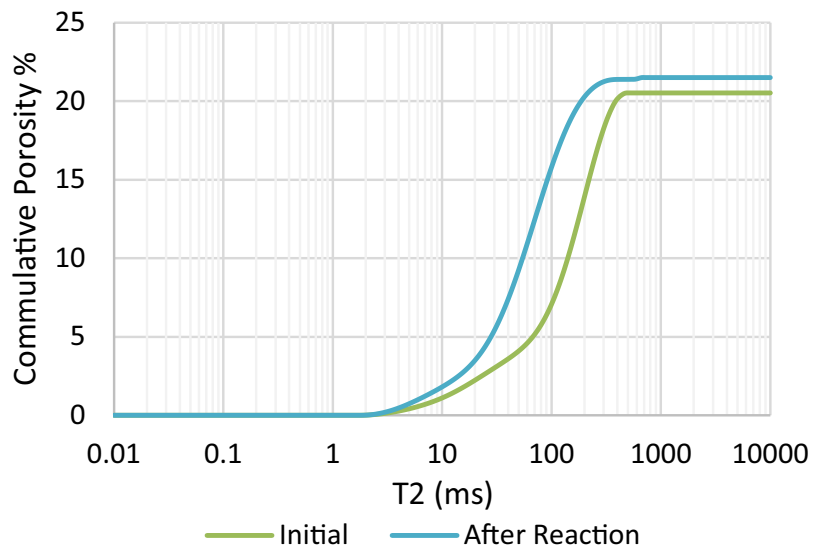

Fig. $15 \mathrm{~T} 2$ commulative spectrum of Berea sandstone core samples before and after reaction with chelates

- Chelating agents change the wettability state of the sandstone core sample toward more water-wet conditions.

- Wormhole analysis showed that HEDTA is effective in creating wormholes in dolomite formations.

- NMR analysis confirmed that HEDTA is more effective in creating new pore spaces in both dolomite and sandstone formations.

Open Access This article is distributed under the terms of the Creative Commons Attribution 4.0 International License (http://creativeco mmons.org/licenses/by/4.0/), which permits unrestricted use, distribution, and reproduction in any medium, provided you give appropriate credit to the original author(s) and the source, provide a link to the Creative Commons license, and indicate if changes were made.

\section{References}

Adler PM, Jacquin CG, Quiblier JA (1990) Flow in simulated porous media. Int J Multi Phase Flow 16:691-712. https://doi. org/10.1016/0301-9322(90)90025-e

Adler PM, Jacquin CG, Thovert JF (1992) The formation factor of reconstructed porous media. Water Resour Res 28:1571-1576. https://doi.org/10.1029/92wr00059

Al-Harthy S (2008) Options for high-temperature well stimulation. Oil Field Rev 20(4):52-62

Allan CC, Tsapin AI, Kuebler K, Haskin L, Wang A (2002) Analysis inside the box- studying rock and soil in biological quarantine. Lunar Planet Sci XXXIII, abstract 1222

Alotaibi M, Nasralla R, Nasr-El-Din H (2011) Wettability studies using low-salinity water in sandstone reservoirs. SPE Reserv Eval Eng 14(06):713-725. https://doi.org/10.2118/149942-pa

Carlson W (2006) Three-dimensional imaging of earth and planetary materials. Earth Planet Sci Lett 249:133-147. https://doi. org/10.1016/j.epsl.2006.06.020

Fourie S (1974) The cranial morphology of Thrinaxondon liohinus Seeley. Ann S Afr Mus 65:337-400

Fredd CN, Tjia R, Fogler HS (1997) The existence of an optimum Damkohler number for matrix stimulation of carbonate 
formations. Society of petroleum engineers, SPE-38167-MS. https ://doi.org/10.2118/38167-MS

Ghommem M, Zhao W, Dyer S, Qiu X, Brady D (2015) Carbonate acidizing: modeling, analysis, and characterization of wormhole formation and propagation. J Pet Sci Eng 131(Supplement C): $18-33$

Hazlett RD (1997) Statistical characterization and stochastic modeling of pore networks in relation to fluid flow. J Math Geol 29:801822. https://doi.org/10.1007/bf02768903

Ji Q, Zhou L, Nasr-El-Din HA (2014) Acidizing sandstone reservoirs using fines control acid, SPE-169395-MS. https://doi. org/10.2118/169395-MS

Johnson LM, Shepherd SD, Rothrock GD, Cairns AJ, Al-Muntasheri GA (2016) Core/shell systems for delayed delivery of concentrated mineral acid, SPE-173734-PA. https://doi.org/10.2118/173734-PA

Joshi M (1974) A class of stochastic models for porous media (Ph.D. thesis). University of Kansas, Lawrence

Leet LD, Judson S (1971) Physical geology. Prentice-Hall, NJ

Mahmoud MA, Nasr-El-Din HA, De Wolf C, Alex A (2011) Sandstone acidizing using a new class of chelating agents. Society of Petroleum Engineers, SPE-139815-MS. https://doi.org/10.2118/13981 5-MS

Marschall DM (2000) HBVI: an NMR method to determine BVI as a function of reservoir capillarity. In: SPWLA 41st annual logging symposium, Dallas, 4-7 June. SPWLA-2000-KK

Mohammadi H, Delshad M, Pope G (2009) Mechanistic modeling of alkaline/surfactant/polymer floods. SPE Reserv Eval Eng 12(04):518-527. https://doi.org/10.2118/110212-pa

OPEC (2016) Oil supply and demand outlook to 2040. World Oil Outlook. A.-M. F. James Griffin. Helferstorferstrasse 17 A-1010 Vienna, Austria, OPEC Secretariat

Øren P-E, Bakke S (2002) Process-based reconstruction of sandstones and prediction of transport properties. Transp Porous Media 46:311-343. https://doi.org/10.1023/a:1015031122338

Saneifar M, Fahes M, Lewis-Hosein R, Hassna B, HIll D (2010) The effect of spent acid on carbonate rock wettability. In: Trinidad and Tobago energy resources conference. http://dx.doi. org/10.2118/133166-ms
Saneifar M, Nasr-El-Din H, Nasralla R, Fahes M, HIll D (2011) Effect of spent acids on the wettability of sandstones and carbonates at high temperature and pressure. In: SPE European formation damage conference. http://dx.doi.org/10.2118/14413 2-ms

Shafiq MU, Mahmud HKB (2017) Sandstone matrix acidizing knowledge and future development. J Petrol Explor Prod Technol. https ://doi.org/10.1007/s13202-017-0314-6

Shafiq MU, Mahmud HKB, Arif M (2018) Mineralogy and pore topology analysis during matrix acidizing of tight sandstone and dolomite formations using chelating agents. J Pet Sci Eng 167:869-876

Sidaoui Z, Sultan AS (2016) Formulating a stable emulsified acid at high temperatures: stability and rheology study, international petroleum technology conference, SPE-19012-MS. https://doi. org/10.2523/IPTC-19012-MS

Smith CF, Hendrickson AR (2013) Hydrofluoric acid stimulation of sandstone reservoirs. J Pet Tech 17(02):215-222

Starkey J, Samantaray AK (1994) A microcomputer-based system for quantitative petrographic analysis. Comput Geosci 20(9):12851296. https://doi.org/10.1016/0098-3004(94)90055-8

Wellington SL, Vinegar HJ (1987) X-ray computerized tomography. J Pet Technol 39:885-898. https://doi.org/10.2118/16983-pa

Xu W, Ayirala S, Rao D (2008) Measurement of surfactant-induced interfacial interactions at reservoir conditions. SPE Reserv Eval Eng 11(01):83-94. https://doi.org/10.2118/96021-pa

Yeong CLY, Torquato S (1998a) Reconstructing random media. Phys Rev E Stat Phys Plasmas Fluids Relat Interdiscip Top 57:495-506

Yeong CLY, Torquato S (1998b) Reconstructing random media. II. Three-dimensional media from two-dimensional cuts. Phys Rev E Stat Phys Plasmas Fluids Relat Interdiscip Top 58:224-233

Publisher's Note Springer Nature remains neutral with regard to jurisdictional claims in published maps and institutional affiliations. 